\title{
Cystatin C and Seminal Parameter Evaluation in Patients with End-Stage Renal Disease
}

\author{
Gilmar Pereira Silva Vitor Pereira Xavier Grangeiro $^{b}$ Carmelita Félix Dantas de Oliveira $^{\mathrm{b}}$ \\ Francisco Lima Netoc
}

aUrologist of the University of Brasilia, Brasilia; ${ }^{b}$ Academic of the Medical Course of the School of Medical Sciences, João Pessoa; 'Academic of the Medicine Course Federal University of Pará, Belém, Brazil

\section{Key Words}

Chronic kidney disease $\cdot$ Hemodialysis $\cdot$ Cystatin $C \cdot$ Semen $•$ Seminal parameter $\cdot$ Male infertility

\begin{abstract}
Objective: We aimed to investigate the possible relationship between seminal parameters and cystatin $C$ seminal levels in an infertility evaluation of chronic hemodialysis patients. Materials and Methods: This was a cross-sectional study, aged 18-60 years, in a group of 60 men undergoing hemodialysis (case) for more than 6 months, and a group of 15 healthy men (control) without clinical or laboratory signs of genitourinary tract infection. We performed a spermogram, hormonal profile, and assessment of leukocytes and cystatin levels in the semen. Results: The ages in the case and control were similar $(p=0.060)$. The seminal cystatin was significantly different between the case group and control group (41.16 \pm 26.59 vs. $79.00 \pm 05.68 \mathrm{mg} / \mathrm{l}$, respectively, $\mathrm{p}<0.001)$ and between normospermia and oligospermia ( $83.50 \pm 02.40$ vs. $30.34 \pm 02.52 \mathrm{mg} / \mathrm{l}$, respectively, $\mathrm{p}<0.001)$. The mean seminal cystatin levels identified by the degrees of oligospermia (severe, moderate, and slim) were similar to each other ( $p$ $>0.05)$ and significantly different $(p<0.05)$ in relation to normospermia in the case group. The seminal cystatin levels positively correlated ( $p<0.05$ ) with sperm motility and sperm density. Conclusion: Seminal cystatin levels are asso-
\end{abstract}

\section{KARGER}

Fax +4161306 1234

E-Mail karger@karger.com

www.karger.com
(C) 2020 The Author(s)

Open access

This article is licensed under the Creative Commons AttributionNonCommercial-NoDerivatives 4.0 International License (CC BYNC-ND) (http://www.karger.com/Services/OpenAccessLicense) Usage and distribution for commercial purposes as well as any distribution of modified material requires written permission. ciated with the numerical and motility changes evidenced in the spermogram and may be of help in the initial evaluation of clinical suspicion of sub-fertility and infertility.

(c) 2020 The Author(s)

Published by S. Karger AG, Basel

\section{Introduction}

Even without associated complications, approximately $15 \%$ of all couples worldwide experience infertility (defined as the inability to conceive after 12 months of timed intercourse) [1] and approximately $40-60 \%$ of infertile males present some alteration in at least one of the seminal parameters (sperm concentration, motility, and morphology) [2]. Seminal analysis by the spermogram is the initial stage of investigation of male infertility, even knowing that this initial analysis is not able to clarify the sub-fertility and infertility cause in a considerable number of cases [3]. Seminal plasma is rich in proteins that have long been studied in search of some that may be associated with changes found in semen parameters that can be useful in clinical differentiation between fertility and infertility status [4].

Chronic kidney disease promotes significant changes in the reproductive tract of both males and females resulting in sub-fertility and infertility by the direct or in-

Gilmar Pereira Silva

North Hotel Sector, Block D

Apartment 1716, Fusion Building

BR-70701-040 Brasilia (Brazil)

E-Mail gilpsilva2006@gmail.com 
Table 1. Comparative evaluation of CysC seminal (mg/l) levels

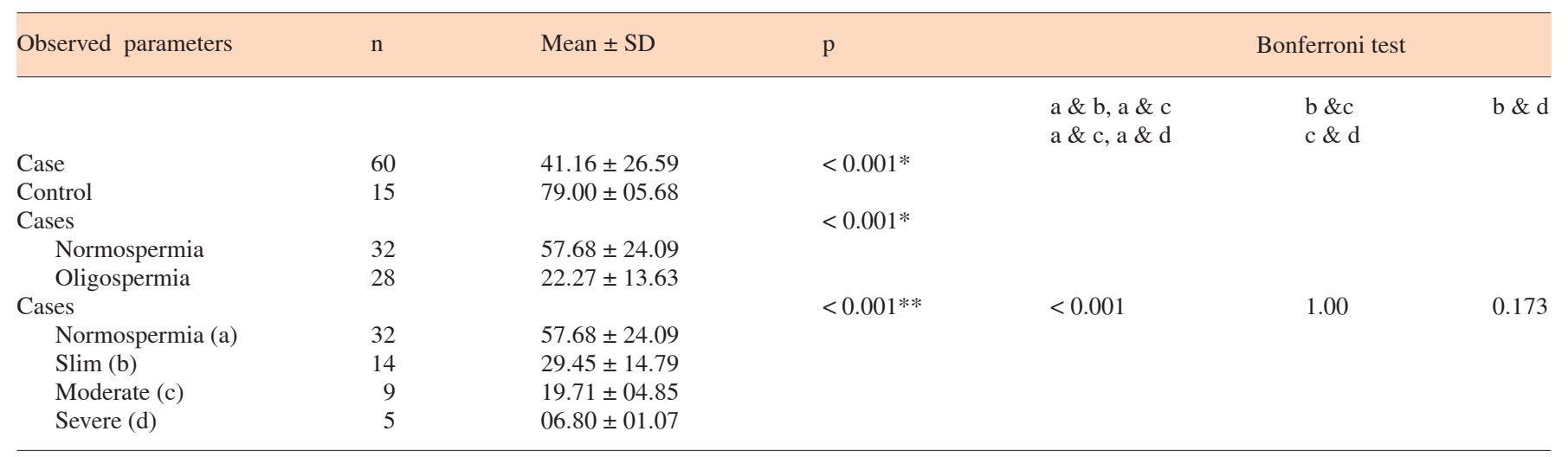

*Mann Whitney; **One-way ANOVA test.

direct effect of uremia and other factors such as systemic inflammation and oxidative stress, genetic, hormonal, and immunological stress on the gonads [2]. Identification of novel biomarkers in order to better understand the pathway and molecular mechanisms in male infertility could significantly contribute to the development of novel therapeutic strategies of male infertility [5]. In this regard, that cystatin $\mathrm{C}(\mathrm{Cys} \mathrm{C})$ is highly expressed and widely distributed throughout the male genital tract, suggests that $\mathrm{CysC}$ is an important regulator for normal and pathological proteolysis in the male reproductive system [6]. Clinically, CysC is mostly used as a biomarker of kidney function to measure the glomerular filtration rate [7] and processes such as tumor invasion and metastasis, inflammatory processes, and some neurological diseases [8].

Considering the high concentration of $\mathrm{CysC}$ in the male reproductive system and that few studies have evaluated its possible association with seminal parameters, we decided to evaluate the possible association between CysC seminal levels and seminal parameters in chronic hemodialysis patients with the perspective of its use as a biomarker.

\section{Materials and Methods}

\section{Recruitment, Inclusion and Exclusion}

The prospective study of the prevalence was done in the Hemodialysis Sector of the University Hospital of the University of Brasilia, between July 2016 and December 2016, after approval by the Research Ethics Committee of the Faculty of Health Sciences of the University of Brasília under number 53172316.9.0000.0030.
Inclusion criterion was age between 18 and 60 years. Exclusion criteria were hypogonadism/hyperprolactinemia; gonadal genetic alterations with Klinefelter syndrome, and problems in ejaculation caused by vas deferens obstruction. Patients with a recent history of genitourinary tract infection and/or prostatitis, cryptorchidism, or varicocele were not included in the study. The sample consisted of 60 men in hemodialysis (case group) for more than 6 months and 15 healthy men (control group) from the health promotion outpatient clinic of the same hospital. During the sample selection process, 21 cases and 10 controls were excluded due to leukocytospermia.

Assessment of leukocytes in the semen was by staining peroxidase-positive granulocytes using ortho-toluidine, according to manual of examination and processing of human semen [9]. Leukocytospermia was defined as the value $<10 \times 10^{6}$ peroxidase-positive cells per $\mathrm{ml}$ as the threshold [9].

\section{Routine Collection of Blood/Semen}

On the first weekly hemodialysis session in the case group and on a previously scheduled day for the control group, blood samples for routine exams and hormonal profile (follicle stimulating hormone, luteinizing hormone, prolactin, and total testosterone) were collected at 8:00-10:00 a.m. and semen samples by voluntary masturbation in an appropriate environment at $37^{\circ} \mathrm{C}$ in order to perform a spermogram by the manual method according to the guidelines of the World Health Organization laboratory manual (5th edition) for the examination and processing of human semen [9]. Seminal plasma was prepared by centrifuging at $3,500 \times \mathrm{g}$ for 20 minutes after 30 minutes liquefaction. The supernatant was collected in a new tube and held at $20^{\circ} \mathrm{C}$ for the measurement of CysC levels by immunoassay using the BNII immunonephelometer (Dade Behring). Specific kits were used for quantification, as well as calibrators and controls recommended by the manufacturer.

After analyzing the variables by normality tests, the most appropriate statistical test was applied to verify differences and correlations between the studied variables. Statistical significance was set at $\mathrm{p}<0.05$ to reject the null hypothesis. SPSS ${ }^{\circledast}$ for Windows, version 20.0 was used. 
Table 2. Pearson's correlation evaluation between CysC seminal levels and seminal parameters in case and control groups

\begin{tabular}{lccccrr}
\hline Observed parameters & \multicolumn{2}{c}{ Case $(\mathrm{n}=60)$} & & \multicolumn{2}{c}{ Control $(\mathrm{n}=15)$} \\
& $\mathrm{r}$ & $\mathrm{p}$ & & $\mathrm{r}$ & $\mathrm{p}$ \\
\hline Seminal CysC & & & & & \\
$\quad$ Sperm motility & 0.467 & 0.030 & & 0.737 & 0.002 \\
Sperm viability & 0.223 & 0.087 & & 0.079 & 0.780 \\
Sperm density & 0.775 & $<0.001$ & & 0.804 & $<0.001$ \\
Sperm morphology & 0.128 & 0.09 & & 0.320 & 0.245 \\
\hline
\end{tabular}

\section{Results}

The ages in the case group and control group were similar $(49.47 \pm 05.55$ vs. $50.53 \pm 04.24$ years, respectively, $\mathrm{p}=0.060$ ). The mean seminal CysC levels were significantly different (table 1) between the case group and control group $(41.16 \pm 26.59$ vs. $79.00 \pm 05.68 \mathrm{mg} / \mathrm{l}$, respectively, $\mathrm{p}<0.001)$ and between normospermia and oligospermia $(83.50 \pm 02.40$ vs. $30.34 \pm 02.52 \mathrm{mg} / \mathrm{l}$, respectively, $\mathrm{p}<0.001)$. The mean seminal CysC levels (table 1) identified by the degrees of oligospermia (severe, moderate, and slim) were similar to each other ( $\mathrm{p}$ $>0.05)$ and significantly different $(\mathrm{p}<0.05)$ in relation to normospermia in the case group. The mean seminal CysC levels correlated $(\mathrm{p}<0.05)$ positively with sperm motility and sperm density in the case and control groups (table 2). All participants presented a normal hormonal profile.

\section{Discussion}

Clinically, CysC, also called cystatin 3, gamma-trace, post-gamma-globulin, or neuroendocrine basic polypeptide, is mostly used to measure the glomerular filtration rate as a marker for kidney function due to its relatively small molecular weight and easy detection [10]. Currently, other possible physiological functions attributed to $\mathrm{CysC}$ are being investigated as to their involvement in processes such as tumor invasion and metastasis, inflammatory processes, and some neurological diseases $[8,11]$. In such diseases the emphasis is placed on the fine balance and regulation of both the cysteine proteases (family cathepsins) and their inhibitors (cystatins and/ or $\alpha 2$-macroglobulin) [12]. CysC has been very poorly studied in infertility investigative studies and there are few studies associating CysC with sperm dysfunctions and the regulatory mechanism of male fertility. In this sense, this study is of importance because the knowledge of using $\mathrm{CysC}$ as a possible biomarker of alterations found in the spermogram.

The age in the case and control groups were similar $(p=0.060$, table 1$)$ which ensured greater reliability, and lowered the impact on the analysis and interpretation of of these variable determinants in the individual variation of seminal parameters due to age.

The mean levels of seminal CysC were significantly lower in the case group in relation to the control group, oligospermia in relation to normospermia (table 1), and the strong positive correlation for sperm density and motility in the case and control groups reinforce this possible relationship between $\mathrm{CysC}$ and seminal parameters (table 2). Our findings are corroborated by other authors. Sharma et al. [13] did proteomic analysis performed by liquid chromatography mass spectrometer analysis (LCMS) in a sample of 21 healthy male volunteers of unproven fertility and 43 males with changes in fertility. They found seminal expression of the $\mathrm{Cys} C$ precursor significantly lower in the group of those with oligozoospermia and abnormal morphology in relation to the group of healthy males and high $\mathrm{CysC}$ precursor levels in groups without oligozoospermia and abnormal morphology. Wu et al. [14] investigated the clinical significance of $\mathrm{CysC}$ in seminal plasma and set its reference range for clinical research in seminal plasma of 192 infertile men and 50 healthy men by the immune colloidal gold technique. They found significantly lower mean CysC concentrations in infertile men $(19.37 \pm 7.43 \mathrm{mg} / \mathrm{l}) \mathrm{com}$ pared to health men $(23.55 \pm 2.50 \mathrm{mg} / \mathrm{l})$, and oligozoospermia $(15.92 \pm 4.96 \mathrm{mg} / \mathrm{l})$. Conti et al. [15] measured average levels of $\mathrm{CysC}$ in cervical mucus and sperm by immunonephelometry for use in treatment and a method of diagnosing and/or predicting sterility and/or infertility of a subject and/or of a couple, and found mean values of CysC concentrations in the seminal fluid obtained from the semen of 31 sterile men was of $31.58 \pm 11.72 \mathrm{ng} /$ $\mathrm{ml}$. The authors [15] also suggested that $30 \%$ of sterile men displayed a concentration of $\mathrm{CysC}$ in the semen which was low to very low, that is less than $30 \mathrm{ng} / \mathrm{ml}$ and which induced disruption of the proteinase/antiproteinase balance which may lead to infertility. The mechanism by which $\mathrm{CysC}$ may be related to human fertility is not well known but it is hypothesized to be related to inhibitory control over cysteine protease human cathepsins L [16]. Cathepsins are abundantly expressed in the testicles [16] and they have the ability to degrade extracellular matrix molecules, including collagens, laminin, 
fibronectin, and proteoglycans and are also involved in the catabolism of intracellular proteins, prohormone processing, and some of these enzymes [17, 18]. Cells with large amounts of cathepsin $L$ are synthesized during stages VI to VII of the cycle of the seminiferous epithelium for quantitatively normal spermatogenesis. Interaction between protease and protease inhibitors seems to be involved in the pathogenesis of inflammatory and malignant diseases [19]. Charron et al. [20] showed that mouse and rat Sertoli cells play an important role in cathepsin $\mathrm{L}$ in remodeling and restructuring of the seminiferous tubules during spermatogenesis [21]. Furthermore, expression of 2-macroglobulin and also of CysC in culture are synergistic in the adherence of germ cells to Sertoli cells and the subsequent formation of intercellular junctions [21]. CysC acts as an efficient inhibitor to balance the activity of cathepsin $\mathrm{L}$ in a specific microenvironment, restricting the action of the enzyme to a specific step of spermatozoa maturation in the distal part of the epididymis and/or at the step of the Sertoli/germinal cell dissociation [22]. On the other hand, it is the consensus that changes in seminal parameters have other important contributing factors such as oxidative stress, systemic inflammation, and genetics [23]. Evidence indicates that
CysC is involved in the complex mechanism of spermatogenesis between $\mathrm{CysC} /$ cathepsin $\mathrm{L}$ synchronic interaction required in spermatogenesis acting as an important regulator for normal and pathological proteolysis and is protection against endogenous proteolysis in the male reproductive system. The action of the $\mathrm{CysC} /$ cathepsin complex partially explains the changes evidenced in the seminal parameter for the existence of other factors involved in the etiology of infertility. These factors alone or together break the contribution to the blood-testicular barrier and the immuno-privileged testicular condition and lead to male infertility [24]. This study has the limitations of absence of supplementary measurement of total seminal antioxidant capacity and reduced sample size.

\section{Conclusion}

Results of this study suggest that the CysC seminal levels are associated numerical and motility changes evidenced in the spermogram and may help in the initial evaluation of patients with clinical suspicion of sub-fertility and infertility. More studies are needed to confirm this hypothesis.

\section{References}

1 Gannon JR, Walsh TJ: The epidemiology of male infertility: biennial review of infertility. Springer, 2015, pp3-7.

-2 Sharma A: Male infertility; evidences, risk factors, causes, diagnosis and management in human. Ann Clin Lab Res 2017;5:188.

3 Aziz N: Interpreting semen analysis and level 2 sperm testing: the diagnosis and treatment of male infertility. Springer, 2017, pp19-31.

4 Barratt CLR, Bjorndahl L, De Jonge CJ, Lamb DJ, Osorio Martini F, McLachlan R, Oates RD, van der Poel S, St John B, Sigman M, Sokol R, Tournaye H: The diagnosis of male infertility: an analysis of the evidence to support the development of global WHO guidance-challenges and future research opportunities. Hum Reprod Update 2017;23: 660-680.

5 Coutton C, Fissore RA, Palermo GD, Stouffs $\mathrm{K}$, Touré A: Male infertility: genetics, mechanism, and therapies. Biomed Res Int 2016; 2016:7372362.

6 Jiborn T, Abrahamson M, Wallin H, Malm J, Lundwall A, Gadaleanu V, Abrahamsson PA, Bjartell A: Cystatin C is highly expressed in the human male reproductive system. J Androl 2004;25:564-572.
-7 Ravn B, Rimes-Stigare C, Bell M, Hansson M, Hansson LO, Martling CR, Larsson A, Martensson J: Creatinine versus cystatin C based glomerular filtration rate in critically ill patients. J Crit Care 2019;52:136-140.

-8 Xu Y, Ding Y, Li X, Wu X: Cystatin C is a disease-associated protein subject to multiple regulation. Immunol Cell Biol 2015;93:442-451.

9 WHO laboratory manual for the examination and processing of human semen. 2010.

10 Qiu X, Liu C, Ye Y, Li H, Chen Y, Fu Y, Liu Z, Huang X, Zhang Y, Liao X, Liu H, Zhao W, Liu $X$ : The diagnostic value of serum creatinine and cystatin $\mathrm{c}$ in evaluating glomerular filtration rate in patients with chronic kidney disease: a systematic literature review and meta-analysis. Oncotarget 2017;8:7298572999.

11 Wisessmith W, Shimizu T, Tanaka K, Ikenaka K: Role of Cathepsin $\mathrm{C}$ and Cystatin $\mathrm{F}$ in demyelinating diseases. Journal Of Neurochemistry 2014;130:58-58.

12 Turk V, Stoka V, Turk D: Cystatins: biochemical and structural properties, and medical relevance. Front Biosci 2008;13:5406-5420.
13 Sharma R, Agarwal A, Mohanty G, Jesudasan R, Gopalan B, Willard B, Yadav SP, Sabanegh E: Functional proteomic analysis of seminal plasma proteins in men with various semen parameters. Reprod Biol Endocrinol 2013;11:38.

14 Wu Y, Zhou X, Wu Z, Lu X, Huang W, Nie $\mathrm{S}$, Yang L: The detection and clinical significance of cystatin $\mathrm{C}$ in seminal plasma. Chinese Journal of Andrology 2008;22:13-16.

15 Conti M, Loric S, Manivet P, Caradec J, Kwemo CK, Matar C, Revaud D: Methods for diagnosing and/or treating sterility, Google Patents, 2015. Available: https://patents.google.com/patent/EP2497490A1/en.

16 Gye MC, Kim ST: Expression of cathepsin L in human testis under diverse infertility conditions. Arch Androl 2004;50:187-191.

17 Li YY, Fang J, Ao GZ: Cathepsin B and L inhibitors: a patent review (2010 - present). Expert Opin Ther Pat 2017;27:643-656.

18 Vidak E, Javoršek U, Vizovišek M, Turk B: Cysteine cathepsins and their extracellular roles: shaping the microenvironment. Cells 2019;8:264. 
19 Khaket TP, Kwon TK, Kang SC: Cathepsins: potent regulators in carcinogenesis. Pharmacol Ther 2019;198:1-19.

20 Charron M, Chern JY, Wright WW: The cathepsin L first intron stimulates gene expression in rat sertoli cells. Biol Reprod 2007; 76:813-824.
21 Chen H, Mruk DD, Lee WM, Cheng CY: Regulation of spermatogenesis by a local functional axis in the testis: role of the basement membrane-derived noncollagenous 1 domain peptide. FASEB J 2017;31:3587-3607.

22 Peloille S, Esnard A, Dacheux JL, Guillou F, Gauthier F, Esnard F: Interactions between ovine cathepsin L, cystatin $\mathrm{C}$ and $\alpha 2$-macroglobulin. Potential role in the genital tract. Eur J Biochem 1997;244:140-146.
23 Zhang Y, Xiao F, Lu S, Song J, Zhang C, Li J, Gu K, Lan A, Lv B, Zhang R, Mo F, Jiang G, Zhang X, Yang X: Research trends and perspectives of male infertility: a bibliometric analysis of 20 years of scientific literature. Andrology 2016;4:990-1001.

24 Fijak M, Bhushan S, Meinhardt A: The immune privilege of the testis; in Krause WK, Naz RK (eds): Immune Infertility, ed 2. Springer, 2017, pp97-107. 